\title{
CONGENITAL BLIND AND SIGHTED; EMOTIONAL INTELLIGENCE DIFFERENCE
}

1. MBBS, FCPS (Psychiatry) Assistant Professor

Head of Department of Psychiatry and Behavioral Sciences Independent Medical College / University Hospital Faisalabad 2. Assistant Professor

Department of Psychiatry and Behavioral Sciences Independent Medical College / University Hospital Faisalabad

\section{Correspondence Address:} Muhammad Aslam Lodhi 2. Assistant Professor

Department of Psychiatry and Behavioral Sciences Independent Medical College / University Hospital Faisalabad aslamkhank60@yahoo.com

Article received on:

30/03/2015

Accepted for publication: 10/09/2015

Received after proof reading: 12/10/2015

\section{INTRODUCTION}

Physical handicap is one of the few problems which engaged serious attention of all civilized nation of the world today. The unfortunate handicap most of the time responded with the rejection of the victim by the society. The consequences thus, spans from birth to old. A disable individual like every other man is a social being and is therefore not different from his ably bodied brethren. However, society hesitates to accept the person, and invariably, focuses its attention on his disabilities rather than on his abilities.

In case of better handling the child might be much able to cope with his/her disability, it is no exaggeration to say that in the background of every individual handicapped child there is always a handicapped family, but better handling of parents can help managing the effects of their disability. ${ }^{1}$
Any disability can hinder the person's normal personality, intellectual and social development. Similarly, blindness as a disability which has vast potential in it to limit the person's interaction with his environment also holds the same destructive powers. Its effects not only limit the person's ability to achieve and learn as the sighted counterparts are used to, but also leave its marks on person's emotional and personality development.

According to Muklebust about 200 years ago when the first school for the blind was set up in Paris, blind children were rarely believed to be educable, though example were lacking of blind students who had distinguish themselves in diverse fields. Those blind people who had attained great academic heights were looked upon as exceptions. ${ }^{2}$ In absence of sight, individual is at serious disadvantages for survival and success later in life. The complications and deprivations start from the birth of the child with visual disability and 
that disability leads to many psychological problems like avoidance and the isolation. ${ }^{3}$ The effects of the disability thus also interfere in one's mental health. It can also have devastating effects on the interpersonal relationships and adaptability of an individual, that is, the components of emotional intelligence.

The children who cannot see can be at serious risk because of the number of obstacles in the development processes, resulting in actual damage to some behavioral mechanism in the baby. The obstacles ranges from absence of eye contact between mother and infant to physical separation of infant and mother because of medical treatment, which increases maternal/paternal anxiety, and reluctance of the mother or father to stimulate the baby. ${ }^{4}$ That in turn further interferes in social and emotional understanding of the world and people around. The social gap continuously increases with the passage of time, leaving the child in state of loneliness especially at the time of adolescence when child has to attain the social relationship.

Perhaps out of fears and uncertainly a blind individual can gain knowledge of the spatial qualities of objects only by touch, in which kinesthetic experiences play an important part. In order to perform any touch observation, direct contact must be had with the object to be observed, herein lies the strength and weakness of touch its strength, because the touch sense convey not only spatial form, but also surface quality, texture, resilience, temperature, weight, and pliability thus going in many ways far beyond impressions resulting from visual observation. However, some time touch fail to give us information about object, because many things are inaccessible (the sun, mountain, building), too small (a fly or an ant) or too fragile (a butterfly, snowflakes) to be observed by touch. ${ }^{5}$ Thus the person fails to achieve the complete concept, ends in uncertainty and frustration, and might also have feelings of insecurity while meeting new people in environment.

The studied that blind individual cannot explain their existence in their real condition and this thing also produce uncertainty and lake of confidence in blind child which become hurdle in their later life ${ }^{6}$, for example, moving airplanes, burning, or boiling and objects which have no shape of their own and must be kept in containers (mercury in thermometers) cannot be directly observed actually one aspect of vision color perception cannot have the actual experience, none consequently any real concept of color, since color worlds are widely used in our world of the seeing, blind individual build up association with certain color which can be verbal, sensory and emotional.

Crome review the literature and explain the de-association with colors. ${ }^{7} \mathrm{He}$ explain that certain things have their color association, for example, the color "white" may for instance de-association with snow and whiteness may become identified with coldness, crispness and clearness. Blind individuals need to be conversant with the most common visual color associations.

The emotional and social development holds language as the main factor involved, which greatly influences the two concepts, Cutforth explained that development also has effected with the disability. ${ }^{8}$ Visual impaired and blind children develop language basically like sighted children. It is particularly important however that simple accurate language is consistently paired with the real object or experience. But it lacks many important, meaningful characteristics, as to understand an apple; the child needs to feel its smooth skin, smell it, bite into it, cut it, and compare the soft mushy inside with the waxy skin.

There are no differences of language development of blind and sighted individual. ${ }^{9}$ He studied the development of language of six blind children for a period of three years, and concluded that on the base of surface the language of blind children seems like that of their sighted pair but when examine for quality, the blind children have less understanding of words as well as symbolic vehicles. Warren reviewed the literature on the language of blind children without additional handicaps ${ }^{10}$, there is evidence of development differences from sighted children in some area 
of language, development, due to poor visual conceptualization, and he/she has poor verbalization then that of sighted part. This deficiency in language skills, and conceptualizing also limit the child's understanding of others emotion, the nature of interaction with others and thus may led to disturb interpersonal relations.

A sample of 20 blinds and 20 sighted children, match on age, sex and education and self-concept was assessed. It was concluded that there is a significant difference in the scores of two groups and found that blind children have poorer self-concept than sighted individuals and therefore their adaptability can be lesser than sighted children. ${ }^{11}$

Mahesh reviewed study on sensory disable (e.g. blind and deaf) and orthopedic handicapped disable children and adolescent's psychological characteristics and their adjustment to their disability focusing on research and conclude that disability generally have a negative effects on adjustment and create more personal, family, social and educational problems than that of non-handicapped. ${ }^{12}$ Singh and Pathak, formulated a study on blind and sighted and concluded that sighted children are more introverted than blinds children therefore their interpersonal relation is more strong than blinds. ${ }^{13}$

The social and psychological implication of blindness far out weights its physical limitation. Thus, in a sense, blindness is probably a greater social and psychological handicap than is warranted by its sensory limitation. During early adolescence the individual is usually pressured to affiliate with the group of peers. This pressure comes from many sources including the family, the school and the age mates. The world of early adolescence is characterized by the prominence of the peer group as a source of influence. ${ }^{14}$ However, in visually impaired this factor is not activated because visually impaired cannot openly enjoy the peer group as they have to spend most of the time at home. This shortage not affects only the victim but also affect their family because child is very dependent on others.
The adolescence whether early or late, holds specific pressures for the child. As the age progresses the child who initially develop identity in terms of peer group, now begins the process of determining who they are in relation to their culture and their society. The adolescents with blindness have to face multiple conflicts, of age and of their disability. Child has to face a confusion state in which they have to adjust but their handicap become hurdle of their adjustment. This state develops a miserable personality. ${ }^{15}$ The personality and social effects of blindness however are similar to those caused by other condition which either handicapped the individual or set him apart in one way or another from the normal, the majority, the customary or better organized. ${ }^{16}$

According to Feld, the child who is congenitally blind experience the world in his own way which is different from that of most other children, and must also cope with special difficulties in getting about. His personality is affected by these differences, and it can be assumed that because of his handicap he is more likely to be under nervous strain and have to harbor feeling of insecurity and frustration. ${ }^{17}$ The child unable to observe the non-verbal cues in conversation, exhibit special difficulties in communication and as the result less likely to develop adequate social relations.

The literature review thus reflect the interpersonal relationships and adaptability deficits as associated with the disability of blindness and point out the dire need to conduct researches on the same. The search in the emotional intelligence issues in adolescents with blindness will help in formulating the strategies, which will maximize their functioning thus reducing the global burden of the disease.

\section{Problem}

Visual sense is the basic sense as we receive the $80 \%$ information through eye. Without visual sense individual cannot built the concrete concept of the external world. When an individual lose their sense of vision they suffer from lot of psychological problems and these problem affect their social, personal and professional life. There are 
many researchers conducted on this spectrum. There are number of discussions either verified or object effect of blindness on the individual's social life. It is very important and sensitive topic because 30 years before this part of the population was ignored and it was thought that cannot play proper role in their family but research indicates that this view in only a misconception. There are so many fields where blind perform like sighted. Inspire of all arguments this concept already exit in our society that blind cannot fulfill the social demand because they have avoidance from society. Current research was also conducted on this issue.

\section{Hypotheses}

There is a significance differences in interpersonal intelligence between blind adolescents and their sighted countered part.

There is a significance differences in adoptability between blind adolescents and their sighted counterpart.

\section{METHODOLOGY}

The present study aimed to explore the difference on the interpersonal relationship between sighted and blind school going adolescents. Furthermore, the second purpose of this study was to examine the difference in adaptability between blind adolescents and their sighted counterparts. This study was conducted using the following steps:

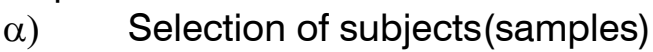

$\beta$ Selection of test instruments

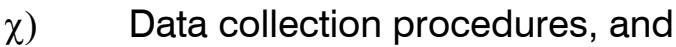

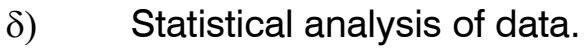

\section{Sample}

In the initial phase of the study entire sample was drawn from the different schools of main stream and special education of Karachi city. Those students were selected from special education institutes who were blind by birth; on the other hand same age group was selected from main stream. Total sixty students were selected randomly from age eleven to eighteen. 30 students were selected from special education institutions, who were congenitally visually impaired and 30 students were selected from main stream; both have equal age group and socioeconomic status.

\section{Measures}

\section{Interview form}

Demographic information was obtained through items which focus on the subject age, gender, religion, and education, number of siblings, birth order, family structure and number of family members.

\section{Baron emotional quotient inventory: youth ver-} sion (baron, \& Parker, 2000)

Baron EQ-1-YU; consist of 60 items distributed on seven scales (Interpersonal, Intrapersonal, Adaptability, stress management, General mood, Positive impression, Inconsistency Index) in this scale is suitable for use of children and adolescents. The Baron EQ-YU uses as 4 point Likert Style format in which respondent in 20 to 25 minutes although it is best administrator on individual but can be administered in groups.

\section{Ethical consideration}

The research was conducted in a manner that respects the dignity, right and welfare and above all protected from possible harm, the person who was the participant of the research. The participants were informed that any information revealed on the questions will be kept strictly confidential and they would have the right to request full anonymity in the study at any time.

\section{Procedure}

Sample of the present study was taken from different schools of main stream and special education located in the different middle class area of Karachi. The entire sample was drawn from middle socioeconomic class.

\section{STATISTICAL ANALYSIS}

After administering the scale two types of information were obtained. First information from blind and second from sighted. After obtaining two independent group of information we administered t-test in order to interpret the data in statis- 
tical terminology.

\section{Research Design}

The research design for the present research was Independent Subject design, which graphically represented below:

\begin{tabular}{|l|l|l|}
\hline Administration of Research & Blind & Sighted \\
\hline Demographic data sheet & 30 & 30 \\
\hline Emotional intelligence scale & 30 & 30 \\
\hline
\end{tabular}

\section{OPERATIONAL DEFINITION OF TERMS}

\section{Blind}

The term include the person who have only light perception without projection, or those who are totally without the sense of vision. ${ }^{18}$

\section{Emotional intelligence}

The ability to monitor one's own and other feelings and emotion to discrimination among them and to use information to guide one's thinking and action. ${ }^{19}$

\section{Interpersonal relationship}

These individuals are likely to have satisfying interpersonal relationship, they are good listener and are able to understand and appreciate the feeling of others.

\section{Adaptability}

These individual are flexible, realistic, and effective in managing change. They are good at finding positive way of dealing with everyday problems.

\section{Adolescence}

Adolescence spans an approximate 10 years period, marked by the onset of pubertal maturation. Pubertal maturation can occur young as 8 years in girls and 9.5 years in boys and late as 13 years in girls and 13.5 years in boys. In term of years adolescent development is not made up of none most homogeneous transition, but rather comprises a number to phases bracketed by ranges of age. In present research only adolescents of early and middle stage will be included, due to the limitation of measures used.

\section{RESULTS}

The present research was conducted to find out the difference in interpersonal relationships and adaptability between the sighted and visual blind school going adolescents. From literature review. It is clear that there are two schools of thought having different point of views related to emotional intelligence of persons suffering from blindness. The present research findings are described in this chapter and the focus is on the detailed statistical analysis of the research data. The data was analyzed using SSPS, v12.0 and significant level of .05 was used for all the analysis.

\begin{tabular}{|c|c|c|}
\hline Variables & Mean & Stander deviation \\
\hline Age & 16 & 1.7 \\
\hline & Table-l. & \\
\hline
\end{tabular}

\begin{tabular}{|c|c|c|}
\hline Variables & N & $\%$ \\
\hline & Education \\
\hline Above Middle & 32 & 52 \\
\hline Below Middle & 28 & 48 \\
\hline & Birth order \\
\hline First born & 18 & 30 \\
\hline Middle born & 26 & 43 \\
\hline Last born & 15 & 25 \\
\hline Only & 1 & 17 \\
\hline & Family system \\
\hline joint & 29 & 48.33 \\
\hline Nuclear & 31 & 51.67 \\
\hline
\end{tabular}

\begin{tabular}{|c|c|c|c|c|c|c|c|c|}
\hline \multicolumn{7}{|c|}{ Hypothesis 1 } \\
\hline Group & N & M & SD & F & Sig & t & df & Sig(2-tailed) \\
\hline Sight & 30 & 29.60 & 3.3 & .000 & .997 & 1.425 & 58 & .160 \\
\hline Blind & 30 & 29.30 & 3.5 & & & & & \\
\hline
\end{tabular}




\begin{tabular}{|c|c|c|c|c|c|c|c|c|}
\hline \multicolumn{7}{|c|}{ Hypothesis 2 } \\
\hline Group & N & M & SD & F & Sig & t & df & Sig (2tailed) \\
\hline Sighted & 30 & 25.47 & 3.411 & 0.200 & 0.66 & 1.906 & 58 & 0.061 \\
\hline Blind & 30 & 23.77 & 3.491 & & & & & \\
\hline
\end{tabular}

DISCUSSION

According previous researches emotional intelligence as the ability to generate, perceive and assess the emotional for assisting thoughts, understanding emotions and emotional knowledge for intellectual and emotional growth. Emotional intelligence has its impact on different life aspects for instance deals with daily life problems and circumstances, how he/she communicates and interacts with others and how he/she adapts the transition of environment. ${ }^{20}$

Blindness is an important issue in our society. Due to difficulties and lack of resources, blind have to face lot of problems in their life. In our society blind people consider as a useless part of society. Their families feel them as a burden and treat them like stranger. This thing produce agitation irritability and lack of confidence and these all factors lead to low self esteem; and poor self concept.

The major role in the better handling and training of blind people is of the parents which can develop competence in them to overcome the devastating effects of their physical limitation. If parents treat them as a normal child and provide all those necessities which are the part of normal growth, then blinds can also play a normal role like a normal/able citizen. Blind children perceive two extreme behavior of his family therefore some flaws lie in their development.

In child rearing practices, child has to face different development changes and parent, siblings and friends support him to tolerate and to adapt to these changes. When a child did not get any proper support from environment, some of their qualities become depressed and individual functioning become disturbed. This attitude not only disturbs blind as well as sighted individuals. If proper support according to age demands, provided to child despite of blindness he/she can become a healthy part of the society but in our society, there are no proper facilities provided to this population. Only 32 institutes are working for this population, which are not sufficient. Especially in Pakistan, the attitude of the people toward any disabilities is awful; so it is this attitude which becomes hurdle in their progress not a disability. Research in this area is limited and requires stress on areas other than intelligence and achievement, so the present study was conducted to evaluate the influence of blindness on their interpersonal relationships and on adaptability. There are two reciprocal views found in different researches, one view that blindness has played no significant role in emotional intelligence (SQ, Ad) and other view that blindness has a great role in their interpersonal intelligence and in adaptability.

Present study failed to establish finding in favor of research hypothesis. It however, adds the evidence in the literature review which is against the view of social limitation in blind people. , according to their study the psychological chasm that separated the blind and the sighted, created and sustained by the tendency of many sighted persons to shrink from interaction with blind. In contrast conducted a study, according to which the personality and the social effects of blindness however are similar to those caused by other condition which either handicapped the individual or set him apart in one way or another from the normal. ${ }^{21}$ In other study also found significant difference in self-concept between residences sighted children and school going blinds. ${ }^{22}$ Similarly, a study to find out the social adjustment of the visually handicapped children in different education setting and found that is no significant difference in social adjustment score. ${ }^{23}$

Results, however, are consistent to Zahron , who administered, among other test, the junior Maudsely personality inventory to the blind and sighted 9-14 years and did not find significant difference 
in extravert although the blind somewhat more introverted. In this context child rearing practice paly a most important role. In the families where proper attention has given toward the difference the children are experiencing being disabled, ${ }^{24}$ handicapped child feel different in social circle; but those who treated in general pattern the handicapped child feel different in social setup( as cited in Begum. ${ }^{25}$ Schulz studied conduct on family relation and social relations and avoid to family members and friends, if family support him/ her and encourage for interaction they become well-adjusted individual of society. Findings thus highlight and can be explained in the context of other related factor. Resulted of the present study prove that not only blindness effect the emotional intelligence, there are so many other factors which can influence the results, and thus need to be addressed.

The problem starts from the birth to old, when a blind diagnose at the time of birth, their parents did not accept it. They start blaming to each other for child disability but with the passage of time they have to accept. In blind child development there are two behaviors observed in our society. In some cases parents become more anxious about the child and ignore their development demands, parents provide everything at bed; they avoid introducing child with others this over protection and pampering generate a pathological state of the child, with the passage of time the blind child fail to perform a normal role in society and become a dependent and disable member of the society. On other hand some parents ignore child and take him as a return of their sins. Parents behave with him as a stranger and feel burden. Both the behaviors from parents can cause pathology and thus need to be addressed in future research.

Along with family variables, the intelligences are also, a factor associated with the emotional intelligence. Present study lacks the control of intelligence. It might be possible that being deprived of sight, the adolescent might focus on other cognitive skills, and thus have superior crystallized intelligence, which facilitate their social interactions and enhance their adaptability. It is thus necessary to design future research projects keeping control of general intelligence and achievement.

A further drawback is the limited sample due to restricted time period. Further research with increasing sample size would yield significant results especially for the variable of adaptability.

\section{CONCLUSION}

Blindness is a great loss, an individual become more depend on others and have to face lot of difficulties. In spite of blindness they have no significant differences in emotional intelligence. Present study concludes that there are no significance differences in emotional intelligence between blind adolescents and there sighted counterpart, which adds evidence in many other studied reporting similar results. This school of thought has strongly refuted that they said that specific personality and environmental factors are also responsible for these problems. However, findings in future need to be addressed in context of available opportunities, age, educational setting and environment, family, personal attitude toward disability, and mainstream interaction.

\section{LIMITATIONS AND SUGGESTIONS}

The sample of the study was limited to only males, because there is lack of special educational institute for females. Future research considering this limitation would be effective.

Age differences play an important role in educational progress in special educational institute age of admission is different to mainstream, so it was difficult to match on educational level, and age and it limit the availability of data. Future longterm projects would be helpful in this instance.

Availability of the participant was difficult so data was very small. There is a need for similar type of studies to be carried out on a large sample of students.

Further study is required to considers various factors which might influence blind individuals like their family setup and there parenting style. 
Findings of the study need to be verified, by controlling the other factors like education, birth order, and academic achievement.

Special educational institutes are not easily available in different areas according to their external setting, so it is difficult to match on residential setting.

Copyright(C) 10 Sep, 2015.

\section{REFERENCES}

1. Baron, R., \& Parker, J. D. A. , Baron Emotional Quotient Inventory: Youth version MHS: New York.2000.

2. Civelli, F. Verbalism in young children. In Kirk, A.S \& Gallaghr J.J. Educating Exceptional children Illinois Lawrenceville. New Jersey: Houghton Mifflin Company. $1983 ; 5^{\text {th }}$ ed.

3. Cromer, R. Conservation by the congenitally blind children. In karik, A.S \&Gallagher, J. J. . Educating Exceptional children ( $5^{\text {th }}$ ed.) Illinois Lawrenceville, New Jersey: Houghton Mifflin Company. 1973-1986, $5^{\text {th }}$ ed.

4. Cutforth, T. D. The blind in school and society. In Begum, S. Cognitive development in blind children. New Delhi, India: Discovery Publisher House.1951;Ed.

5. Deshmuk, K Personality characteristics of the physically handicapped. In Rai, N.K Visual handicaps and personality dynamic . Delhi, India: Academic excellence1980-2005; 55.

6. Faye, The low vision patient. In Rai, N.K . Visual handicaps and personality dynamics. Delhi. India: Academic excellence.1970-2005; 6(34).

7. Feld, L. In The International Encyclopedia of Education. In Kirk, A.S \& Gallaghar, J.J. Educational children. Illinois Lawrenceville, New Jersey: Houghton Mifflin Company. 1968-1986; $5^{\text {th }}$ ed.

8. Freiberg, S. Parallel and divergent pattern in blind and sighted infant psychometric study of child. In Begum, S. (Ed.). Cognitive development in blind children. New Delhi, India: Discovery Publisher house.1986;9:115.

9. Garden, K. Emotional Intelligence and borderline personality disorder. Retrieved at April, from www. Psychnet_uk. Com. April, 24:2006-2008.

10. Head, D. A comparison of self-concept score for visually impaired adolescents in several class setting. In Kirk, A.S \& Gallaghar J. J. Educating exceptional children. Illinois Lawrenceville, New Jersey: Houghton Mifflin Company1979-1986; $5^{\text {th }}$ ed.
11. Mayer, W. \& Salve, T. Emotional intelligence. Retrieved at from www. Psychnet_uk.com.December.1989-2008;44;269-74.

12. Mayer, J. \& Solvery, P., Reliance: Emotional Intelligence. Retrieved, from www. Mentalhealth.net/poc/ viewparker,March,6;1990-2008.

13. Meighan, T. An investigation of the self-concept of blind and sighted. In Rai, N. K. Visual handicaps and personality dynamics. Delhi, India, Academic excellence.1971-2005;121.

14. Mahesh, B. Severity of psychological studies. In Rai, N. $\mathrm{K}$. Visual handicaps and personality dynamic. Delhi, India: Academic excellence.1984-2005;312.

15. Muklebust, R. H. The nature and the extent of deafness. In Rai, N.K. Visual handicaps and personality dynamics . Delhi, India, Academic excellence.1964-2005;77.

16. Rai, N.K. Visual handicaps and personality dynamic. Delhi, India: Academic excellence.2005;55.

17. Sanford, N. Psychological phenomena. In Kirk, A.S., \&Gallaghar J. J. Educating Exceptional children . Illinois Lawrenceville, New Jersey: Houghton Mifflin Company.1979-1986; 5th ed.

18. Schulz, J. P. The sight of blindness and phenomena of avoidance. In Kirk, A.S \& Glaaghar, J.J. Educating exceptional children. Illinois Lawrenceville, New Jersey: Houghton Mifflin Company.1975-1986; 5th ed.

19. Steinberg, T. Preparing to parent the Adolescent. Journal of child and Adolescent Psychiatric Nursing, Retrieve from http://www. Blackwell-synergy.october, 10;1987-2008;5(1);32-40

20. Sheridan, $\mathrm{H}$. The handicap children and his home. London: National children home.1981;54;7.

21. Simon, M. J. Some parent child relationship in clinical studies contribution to education. In Rai, N.K. Visual handicap and personality dynamics. Delhi: Academic excellence.1936-2009; 13.

22. Sing, T. B., \& Pattak, K. C. A personality study of visuals handicapped person. 1984.

23. Rai, N.K, Visual handicaps and personality dynamics. Delhi, India, Academic excellence.2005;67;12.

24. Singh, U.P., \& Akhter, S. N. A comparative study of the self concept of visually handicapped and sighted children. In Rai, N.K. Visual handicaps and personality dynamics. Delhi: Academic excellence.1971-2008; 98; 9.

25. Spungin, S, Guidelines for public school programmed 
serving visually handicapped children. In Kirk, A.S. \& Gallaghar J.J, Educating Exceptional children, Illinois
Lawrenceville, New Jersey: Houghton Mifflin Company. $1981-1986 ; 9^{\text {th }}$ ed; $7 ; 98$.

\title{
PREVIOUS RELATED STUDY
}

Muhammad Sultan, Muhammad Khalid Dogar, Zia ud Din Ahmad. INCIDENCE OF RUBELLA IN PATIENTS PRESENTING WITH CONGENITAL OCULAR DEFECTS (Original) Prof Med Jour 10(3) 239 - 243 Jul, Aug, Sep, 2003.

Nageen Hussain. CONGENITAL RUBELLA SYNDROME (Review) Prof Med Jour 13(1) 11-16 Jan, Feb, Mar, 2006.

Shamama Hasan, Huma Farrukh, Ameen ullah, Nadeem Sadiq. CONGENITAL MALFORMATIONS (Original) Prof Med Jour 17(1) 140-144 Jan, Feb, Mar 2010.

\section{"Forgiveness is the best victory."}

\author{
Ali Bin Abi Talib
}

\begin{tabular}{|c|l|l|l|}
\hline \multicolumn{4}{|c|}{ AUTHORSHIP AND CONTRIBUTION DECLARATION } \\
\hline Sr. \# & \multicolumn{1}{|c|}{ Author-s Full Name } & \multicolumn{1}{|c|}{ Contribution to the paper } & Author=s Signature \\
\hline 1 & Dr. Muhammad Arshad & Write Up & $\begin{array}{l}\text { Data collection and } \\
\text { satistical analysis }\end{array}$ \\
\hline 2 & Muhammad Aslam Lodhi & \\
\hline
\end{tabular}

